\title{
Antecedents-Consequences Modification to Decrease Hyperac- tivity and Improve Attention of Child with ADHD
}

\author{
Surya Cahyadi ${ }^{1}$ \\ Faculty of Psychology, Padjadjaran University \\ Puspita Adhi Kusuma Wijayanti ${ }^{2}$ \\ Faculty of Psychology, Padjadjaran University
}

DOI: $\underline{\text { https://doi.org/10.21009/JPUD.132.03 }}$

Accepted: August $15^{\text {th }}$ 2019.Approved: September $4^{\text {th }} 2019$. Published: $30^{\text {th }}$ November 2019

ABSTRACT: The prevalence of ADHD children increases every year. Some researchers have shown that psychosocial behavior therapy (antecedents-consequences modification) was effective to decrease hyperactivity and increase attention to ADHD children. This study aims to find out the effectiveness of antecedents-consequences modification by parents and teachers to decrease hyperactivity and increase attention to a 6 years old boy with ADHD. The study was a single case experimental design. Psychosocial behavior therapy has been used with antecedents-consequences modification. The antecedents-consequences modification was applied by teacher at school and parents at home. Data were analyzed using Wilcoxon Signed Rank Test. Results showed that there's a significant decrease of hyperactivity behavior and significant increase of doing his assignment both at school and also at home. Not only about the content of behavior therapy itself, but how to give the therapy is important. Parents and teacher should do the therapy consistently, immediately, specifically and saliency to reach the target of intervention.

Keywords: ADHD children, antecedents, consequences, modification

\footnotetext{
${ }^{1}$ Corresponding Author:

Surya Cahyadi

Email:surya@unpad.ac.id

${ }^{2}$ Email: puspita.adhi@unpad.ac.id
} 


\section{INTRODUCTION}

ADHD (Attention Deficit/ Hyperactivity Disorder) is the development resistance characterized with inconsistent attention, excessive activity, and impulsive behavior (Nigg, J.T ; Barkley, 2014). The symptoms often appear during the early years of school (U.S. Department of Health and Human Services, 2014) and remain fairly stable during development (Riddle et al., 2013). They often make noise in class and tend to often fight (especially boys). They fail to follow or remember instructions and even complete assignments. They most likely have learning difficulties, repeat classes, and are placed in special classes (Davidson, 2010).

A wide range of research on the prevalence of ADHD in the world increase from year to year. A result of the analysis on the reports by parents based on the National Health Interview Survey (NHIS) 2011 - 2013 showing that there was an increase in children diagnosed with ADHD by $7.0 \%$ in $1997-1999$ to $10.2 \%$ in $2012-2014$. The survey also reports that $9.5 \%$ of children aged 4-17 years were diagnosed ADHD. The analysis was performed based on age groups, $2.7 \%$ of children in the ages of 4-5 years was diagnosed with ADHD; $9.5 \%$ of children in the ages of $6-$ 11 years, and $11.8 \%$ of children in the ages of $12-17$ years. From the data obtained, there were $13.3 \%$ of boys and $5.6 \%$ of girls experiencing ADHD (Pastor, Reuben, Duran, \& Hawkins, 2015). A meta-analysis study of 175 research around the world regarding the prevalence of ADHD to 18 years old children and below determines the population of $7.2 \%$. The population of $7.2 \%$ is derived from a total population of 129 million children around the world (Thomas, Sanders, Doust, Beller, \& Glasziou, 2015). The increasing prevalence from year to year is urgent for educational practitioners, parents, and teachers to intervene in order to decrease hyperactivity and increasing attention in children with ADHD. This is because ADHD affects academic performance, social ability, and quality of life in their adult stage later on (Saputro, 2009).

Various intervention was effective to decrease hyperactivity and increase inattention to children with ADHD, such as psychosocial treatment with behavior therapy (Linda J Pfiffner \& Haack, 2014) and medication (Taylor, 2009). Most professional believe that effective psychosocial treatment is the backbone of good intervention for ADHD (Center for Children and Families, 2019), while medication is not always effective or acceptable to patients and their parents and giving side effect. Medication is often used to treat severe ADHD and adults with ADHD, while children is not recommended using medication (Baumeister et al., 2018). In Indonesia, few researches have examined the effectiveness of behavior therapy, most researches using music therapy (Suyanto \& Wimbarti, 2019) and also play therapy (Amalia, 2018; Erinta, 2012). Treatments using music therapy is not always recommended, because the standard for music therapy itself. This is related to the type of musical instrument, number of beats and tones (Jackson, 2003). Besides that, not all cities in Indonesia have music therapy facilities, so parents with ADHD children will difficult to seek help for their children.

Behavior therapy with time-out has been used to treat 2 children with ADHD (age 3-10 years), and significantly effective to decrease hyperactivity (Hidayati, DM Ria; Purwandari, 2010) but actually some professional recommended using behavior therapy with psychosocial treatment to treat children with ADHD (Center for Children and Families, 2019). Time-out was less effective to treat children with ADHD, because they paid more attention to reward than punishment, and time out was considered as a punishment cues (Haas et al., 2011). Psychosocial treatments are regarded as the most effective treatments for children with ADHD because the treatments teach skills to parents and teachers to overcome children's impairments. ADHD is a chronic condition, teaching skills help overcome their impairments and are useful for a child's lifetime (Center for 
Children and Families, 2019). In the psychosocial treatments, teacher and parents are taught to conduct behavioral therapy because they interact with the children in daily life, but unfortunately, few researches in Indonesia study about psychosocial treatments for children with ADHD.

\section{THEORITICAL STUDY}

\subsection{Children with ADHD}

The essential feature of ADHD is a persistent pattern of attention and/or hyperactivity-impulsivity that interferes with functioning or development. Inattention manifest behaviorally in ADHD as wandering off task, lacking persistence, having difficulty sustaining focus, and being disorganized and is not due to defiance or lack of comprehension. Hyperactivity refers to excessive motor activity (such as a child running about) when it is not appropriate, or excessive fidgeting, tapping or talkativeness ((APA), 2013).

ADHD affects academic performance, social ability, and quality of life in their adult stage later on. ADHD in children result less optimal learning achievement even at low levels of achievement and poor psychomotor performance as a result of the difficulties in coordination functions, emotional responses, social skills, and learning skills (Saputro, 2009). Children with ADHD are more likely to fail to finishing the assignments, being suspended from school, and requires advanced interventions during adolescence, compared to other peers (Davidson, 2010). The one of shortterm impacts of ADHD children is social interaction problem including conflict with the family and friendship, such as the refusal of peers which is quite frequent (L. J. Pfiffner, Calzada, \& McBurnett, 2000). In fact, follow-up studies show that children with ADHD have interpersonal problems and risks for educational problems, and the girls had a greater risk for hurting themselves and committing suicide (Stephen P. Hinshaw et al., 2012).

Many ADHD children experienced low academic achievement (Barkley, 2006). In class ADHD children often show behavioral problems. ADHD children have more difficulties to respond instruction and less able to complete academic assignments compared with their peers (Pfiffner, L. $\mathrm{J}$; Barkley, 1990). More than $80 \%$ of children with ADHD were found having learning problems, and some of them were included as underachievers in their adolescent (having low academic achievement but good cognitive abilities) (Cantwell \& Baker, 1991). Due to low academic achievement, many ADHD children (about $40 \%$ ) are placed in a special education program including children with learning disabilities and children with behavioral disorders so that the number of dropped-out ADHD children become higher with approximately 10\% (Barkley, Russell A; DuPaul, G.L ; McMurray, 1990). In adolescence only 20\% of ADHD children can continue their education to the higher-level education (Weiss, Gabrielle; Hechtman, 1993).

\subsection{Behavioral Psychosocial Treatments with Antecedents-Consequences Modification}

A number of researches determine the effectiveness of behavioral therapy for children with ADHD. Some behavior interventions are effective to ADHD Children (Linda J Pfiffner \& Haack, 2014). Children with ADHD are often inattentive, unorganized, off-task, destructive, and demonstrating low completing tasks, both at school and also at home (Langberg et al., 2011). At home, treatments aimed to form children's behavior. Usually parents of children with ADHD show more negative, ineffective, and less warm parenting because increasing conflict at home (Gerdes, Hoza, \& Pelham, 2003; Johnston, Charlotte; Mash, 2001). Behavior management interventions such as parenting training aimed to enhance parenting to improve child and parents' behavior, so this way 
could reduce family conflict (Linda J Pfiffner \& Haack, 2014). But some professional believe that best behavior therapy for children is not only conducted at home, but also at school (psychosocial treatments).

Children with ADHD get more benefit from behavioral psychosocial treatments to improve attention and productivity rather than traditional ADHD medication treatments or other behavioral therapies (Tran et al., 2018). A study compared the efficacy of a behavioral psychosocial treatment integrated across home and school with parent-focused treatment (PFT) and treatment as usual (TFU) for children with ADHD. The study reported that behavioral psychosocial treatment resulted in greater improvements in teacher-reported inattention, organizational skills, social skills and global functioning relative to both PFT and TFU at posttreatments. Parents also reported that their children showed greater improvement in organizational skills than PFT and TFU (Linda J. Pfiffner et al., 2014).

Psychosocial treatments (involve parents and teachers to conduct the behavior therapy) is now recommended as one of important element in multi-modal intervention for ADHD children, especially for the children at the PAUD level (early age education level) (Center for Children and Families, 2019). Based on social learning principles theory, more intervention approaches aim to use adult such as parents, to increase positive behaviors and reduce behavior problems in children (Fabiano et al., 2009; Helseth et al., 2015). Parenting training in the BTP is focused to increasing the expected behavior and decrease problematic behaviors through modification of antecedents and consequences (Anastopoulos, A.D; Farley, 2003; Kaiser, McBurnett, \& Pfiffner, 2011).

Some experts said that some of problems that occur in ADHD children affected by reinforcement of the environment. The pattern of these interactions is often viewed as coercive process, i.e. a circle where children and parents control the behavior of one another through the negative reinforcement (Patterson, 1982). For example, this process occurs when the children exhibit behavior that not appropriate with expectations of parents (does not obey the parent's command) and then parents respond negatively by creating a circle of accusing with high tone. Many of the problems on ADHD children is reinforced by this process. Though it is not due to the ADHD problem, such a child-parent coercive interaction will make negative impacts such as low academic achievement, peer relationships, social skills, and aggressive behavior (S. P. Hinshaw et al., 2000; Kaiser et al., 2011). Thus, the behavior management training is directly targeted on parenting practices to reduce the coercive processes and to enhance the children's behavior and the relationships with the family (Linda J Pfiffner \& Haack, 2014).

Effective treatment for students with ADHD is through behavior therapy that includes strategies based on antecedent-consequence (Barkley, 2006) . Furthermore, he explained the concept of antecedent-consequences modification is basic models of operant conditioning, namely the concept of A-B-C (Antecedents-Behavior-Consequences). Antecedents (Stimulus Discriminative) is a stimulus which was created to provoke a response (Behavior) which is then followed by a reinforcing stimulus (Consequences). Consequences is any stimulus, such as events or consequences that can increase the chances of a response that is expected to reappear (Schunk, 2012). Rules become very important and weak response (no reinforcement) from environment caused the emergence of ADHD. If there are no rules, children won't understand what to do, and no reinforcement will make them do not recognize whether their behavior is acceptable or not in their environment. So, the intervention with behavior therapy directly targets to these deficiencies. An antecedentbased intervention has been widely used to prevent inattention and disruptive behavior. Antecedent will give children cues what behavior they should do. First of all, the teacher can strategically 
place the class rules (DuPaul \& Weyandt, 2006). Rules should be slight and expressed in the positive behavior (for example say to students what to do, not just the behavior that should be avoided), and puts the rules that can be viewed by all students. Furthermore, teachers should regularly praise the students who follow the class rule. Children with ADHD need more intense rules and must be provided with more praise when they obey the rules (Pfiffner, Linda J; Barkley, R; DuPaul, 2006).

The antecedent-based strategy is frequently recommended in students with ADHD to increase engagement in the task by modifying the length of workmanship and the quality of the task (DuPaul, George; Stoner, 2003). Reducing the length of task completion is associated with the students' attention span, reduction of off-task behavior, and disruptive behavior. This strategy is often paired with teacher praise when the task is completed. As long as students demonstrate their success in doing tasks, the length of time of task completion can be increased in stages thereby forming behavior of following and obeying class rules.

In addition to modifying the antecedents, consequence-based strategies could be performed through environmental manipulation after the behavior. A study has reported an effectiveness of consequence-based strategies in ADHD children using contingent positive reinforcement and response cost (DuPaul \& Weyandt, 2006). The use of contingent positive reinforcement example praise from teachers or token reinforcement is effective in forming the expected behavior (DuPaul, George; Stoner, 2003).

The importance of psychosocial treatments using behavioral therapy (antecedents and consequences modification) makes the researcher interested in exploring the effectiveness of behavioral psychosocial treatment based on modification of antecedents-consequences in ADHD children. The uniqueness of the present research lies in comprehensive therapy involving teachers and parents as the therapy practitioners, which in Indonesia is still a little that would examine it. The hypothesis of this research is the antecedents and consequences modification by parents and teachers are effectively decrease hyperactivity and improve attention on ADHD children.

\section{METHODS}

This research is single case experimental design because researchers want to determine the effectiveness of a treatment. Single case experimental designs refers to a set of experimental methods that can be used to test the efficacy of an intervention using a small number of patients (typically one to three), and involve repeated measurements, sequential introduction of an intervention, specific data analysis and statistics (Krasny-Pacini \& Evans, 2018). In the single case experimental design, participant was measured repeatedly and frequently the outcome in all phases of the study, at minimum two phases, generally baseline (by convention designates with the letter, A) and treatment or intervention phase (designated with the letter, B) (Krasny-Pacini \& Evans, 2018). In this study, researcher used 3 phases, A-B-A, because we wanted to know the effectivity of treatments after intervention (follow-up)). Phase A was a phase of baseline that contains of a number series observation of the behavior in the target in a natural situation (before he gets the intervention). Phase $\mathrm{B}$ was the phase in which the intervention or treatment was given, by observing the changes in dependent variable. Measurements are continuing after treatment (Phase A) (Barlow, D.H ; Hersen, 1984). 
Table 1. Experiment Design

\begin{tabular}{ccc}
\hline Phase A & Phase B: & Phase A: \\
Baseline & Intervention & Follow up \\
$\mathrm{X}$ & $\mathrm{O}$ & $\mathrm{X}$ \\
\hline
\end{tabular}

The measuring instrument used behavioral observation during the baseline phase, intervention, and follow-up. Measurements include dependent variables, which is the span of attention and hyperactivity. Baseline measurements were performed over 6 times (Shriver, Segool, \& Gortmaker, 2011). Observations were carried out for 28 times, i.e., 6 times in the baseline phase, 16 times in the intervention phase, and 6 times in the follow-up phase. The number of baselines contributes to the strength of the experimental results, where the minimum number of baselines is 2. If the number of baselines a lot is 5 times and one of the five measurements is not different, the influence of the intervention will be very clear (Kazdin, 1984).

This design contains several numbers in every phase, 6 times in baseline phase, 16 times in intervention phase and 6 times in follow up. When repeated measurements are taken during the baseline phase, several threats to internal validity are controlled. Data were analyzed using the Wilcoxon Sign Rank Test. The researcher used the Wilcoxon Sign Rank Test analysis because the data distribution was not normal. The analysis was done by comparing the baseline phase, the intervention phase, and the follow-up phase.

\subsection{Subject}

This research is a single case experimental design, with one single subject of research that meets the criteria of the study. Criteria of the subject were listed below:

- A boy. The researcher took the sample of a boy because ma ADHD children are much greater than that of girls by comparison $13.3 \%$ for boys and 5.6\% for girls (Thomas et al, 2015).

- The age is 6 years old. The researcher took the sample of 6 years old because this age is a starting point of a child suspected or diagnosed ADHD by teachers or parents. If the diagnosis is done early, the intervention can be performed immediately. More early intervention, the risk of appearance ADHD behavior symptom in the next age will be getting smaller and the negative impact will be smaller.

- At the kindergarten class B. The criteria were used because the kindergarten level (school) is the prevalence of ADHD often found, and the assumption that teachers may also intervene in the school so that the success of the interventions is increasingly achieved fast.

- Availability of parents, teachers, and schools as the subject of the research. It is considered very important for the researcher because without availability and cooperation of the parties, the research will be accomplished.

- Diagnosed ADHD. Diagnosis uses Vanderbilt ADHD Diagnostic Rating Scale (American Academy of Pediatrics and National Initiative for Children's Healthcare Quality, 2002).

Based on the above criteria, there was 1 of 6 years old boy, diagnosed with ADHD and there was willingness of teachers and parents to cooperate in this research. 


\subsection{Assessment}

\subsubsection{Enforcement of Diagnosis}

Diagnosis was enforced based on criteria of diagnosis DSM V (2013) about Attention Hyperactive Disorder derived from Vanderbilt ADHD Diagnostic Rating Scale. Vanderbilt Rating Scale is filled out by parents and teachers that daily interacted with the subject. Teachers and parents were asked to do a rating based on the subject's behavior indicators in the Vanderbilt ADHD Diagnostic Rating Scale. In addition to filling the questionnaire based on the rating scale, teachers and parents were also interviewed by a psychologist. Enforcement of the diagnosis was performed by a psychologist.

\subsubsection{Determining the Identification of the Problem / Target Intervention.}

Based on the analysis of the problem completed through filling in questionnaires of rating scale and the interview, the researcher and the psychologist focused on three problem areas, which were also the targets of intervention. They are:

- reducing the behavior of standing and walking in the classroom during the learning process.

- increasing the range of concentration on-task undertaken at the school.

- increasing the span of concentration on-task at home.

\subsubsection{Determining the Behavior Baseline}

Baseline determining procedure was performed through observation and interview. The observed behaviors were hyperactivity-impulsiveness and lack of attention during the learning process. The behavior was recorded by the momentary event sampling method. The sample of behaviors was taken during the lessons and work tasks at home.

- The behavior of hyperactivity at school were counted when the subject left his seat when the teacher explained the lesson and ran out of class when working on assignments for a 2-hour lesson.

- Attention was calculated from the time of subject could sit quietly finishing his work on school assignments.

- Attention at home is calculated from the time the subject can sit quietly focusing on tasks at home.

\subsection{Intervention}

The behavior therapy based on antecedents-consequences modification to the subject were given by teachers and parents because teachers and parents directly interacted with the subject in daily life. Behavioral therapy procedures given by teachers and parents were through the psychoeducation, ranging from definition and the scope of ADHD, the impact brought about if not well handled, and then the procedure of delivering the behavioral therapy.

The intervention was carried out at home and school with the goal of keeping the subject familiar/consistent with new patterns of behavior. This way made the success of intervention achieved more quickly. The psychoeducation performed was as follow. 


\subsubsection{Psychoeducation of parents}

Explain to parents about antecedents-consequences based behavioral therapy that can be given to the subject at home. Antecedents are modified by creating rules at home that are placed in the subject's room visually and there are symbol images. Consequences in the form of father and mother are asked to provide positive reinforcement in the form of praise, hugs and kisses on the subject if he is obedient and follows the orders of the father and mother, for example if the subject is obedient to sit quietly doing the task, the parent provides positive reinforcement in the form of hugs, praise or kisses. This is done considering that the subject is happy if he gets the attention of the father and mother. The rules are given to the subject:

- obeying the commandments of the father and mother

- speaking politely and responding well if called or asked mom and dad.

- behave politely, no stair climbing and no running around the house.

\subsubsection{Psychoeducation of teachers}

Explain to the teacher about the behavioral therapy procedures that can be performed by teachers through modifying antecedents and consequences.

\subsubsection{Modification of Antecedents}

Emphasize more rules in the class. Rules are given by the teacher in verbal form when the lesson starts and between lessons. Rules are given to the students:

- No run in the class

- Sit quietly when teacher explains

- $\quad$ Finish the task

\subsubsection{Modification of Consequences}

Use positive reinforcement to each student's behavior that is obedient, not run around and be able to sit quietly during the teacher explained the lesson and doing the task. Positive reinforcement is given in the form of a compliment as that children with ADHD need more regulation and should be provided with more praise when they obey the rules.

- Use positive reinforcement if he obeys the rules (no run in the class and sit quietly when teacher explains).

When the subject obeys the rules, teachers give the praise to the students.

- Use positive reinforcement in task completion.

When the subject was successfully complete his task, he was given positive reinforcement in the form of stamp on the workbook with a picture of a train because it was one of the favorite toys of the subject. The stamp scale ranges from 1-4 where: (1) 1 stamp was the indicator that the subject works on the given task but it is not completed (2) 2 stamps was the indicator that the work is completed but he is careless and does mistakes and not follow the teacher's instructions) (3) 3 stamps was the indicator that the subject performs the task in accordance with the teacher's instructions. (4) 4 stamps were the indicator that the subject successfully executes tasks and there is creativity in doing the task. 
Stamps was given immediately on the task submission so that the subject can feel the impact of what he accomplishes.

\section{RESULT AND DISCUSSION}

\subsection{Result}

The results of 4-week implementation of behavioral therapy through modification of antecedentsconsequences by teachers and parents are as follow.

\subsubsection{Hyperactivity in the Class}

The subject had decreased his hyperactivity behaviour, either when the teacher explained the lesson, nor when working on tasks. On the first day of implementation of the intervention, the hyperactive behaviour of the subject did not decline, while entering the third day the hyperactive behaviour of the subject was declining. The behaviour of running around the classroom and running out of the class during task completion decreased from day to day during the process of implementation of the intervention. The decrease in hyperactivity behaviour of the subject can be seen in the graph below.

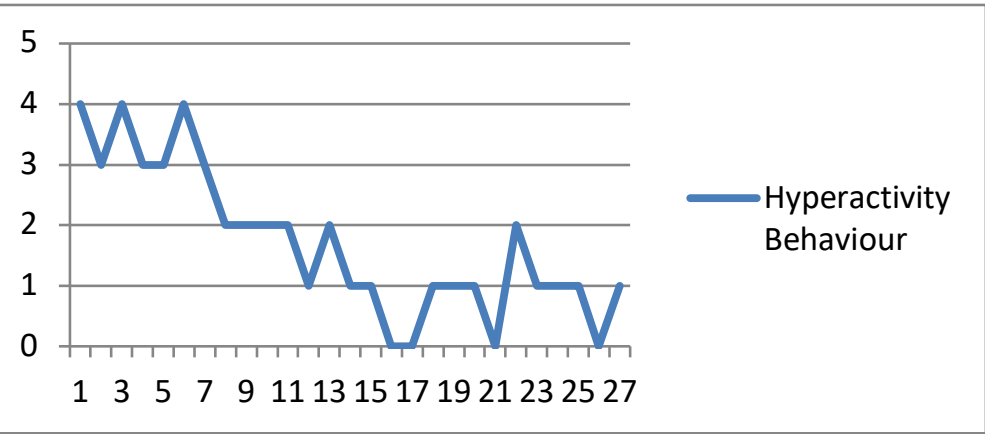

Figure 1 . The decrease in hyperactivity behaviour in the class

Note:

$\mathrm{X}$ axis $\quad=$ The Frequency of Hyperactivity Behaviour

$\mathrm{Y}$ axis = Day

The results of the analysis show that there is a decrease in hyperactivity behavior in the classroom was significant during the baseline, intervention, and follow-up phases, which is indicated by the following table:

Table 1: Descriptive statistics of the decline of hyperactivity behavior in the class

\begin{tabular}{llllll}
\hline Phase & $\mathrm{N}$ & Mean & Std. Deviation & Minimum & Maximum \\
\hline Baseline & 6 & 3.5000 & .54772 & 3.00 & 4.00 \\
\hline Intervention & 16 & 1.1875 & .91059 & .00 & 3.00 \\
\hline Follow-sup & 6 & 1.0000 & .63246 & .00 & 2.00
\end{tabular}

Table 2. Results of analysis of hyperactivity decline in class

\begin{tabular}{llll}
\hline & Intervention-Baseline & Follow Up-Intervention & Follow Up-Baseline \\
\hline $\mathrm{Z}$ & $-2.264^{\mathrm{a}}$ & $-2.121^{\mathrm{a}}$ & $-2.251^{\mathrm{a}}$ \\
\hline Asymp.Sig. (2-tailed) & .024 & .034 & .024 \\
\hline
\end{tabular}


a. Based on positive ranks

b. Wilcoxon Signed Ranks Test

Based on the results, it is determined that the hyperactivity behavior of the subject decreased significantly between the baseline phase to the intervention phase with the value of $p=0.024(p$ $<0.05$ ) and the value of $Z=-2.060$. The decrease in hyperactivity also occurred between the interventions and follow-up phases with the value of $p=0.034(p<0.05)$ and after the therapy was not given, the subject's behavior was consistent that there were differences between the baseline phase with the follow-up phase, which shown with the value of $\mathrm{p}=0.024(\mathrm{p}<0.05)$ and the value of $\mathrm{Z}=-2.251$.

\subsubsection{Time range of task completion at school}

Subjects experienced the increase of on-task completion. Before the intervention, the subject worked on one task for 5-8 minutes in average, then he left that task and then run around the class. During the intervention, the subject could sit in working on one task for 10-20 minutes in average. The increase of the concentration of the subject is presented in the following graph.

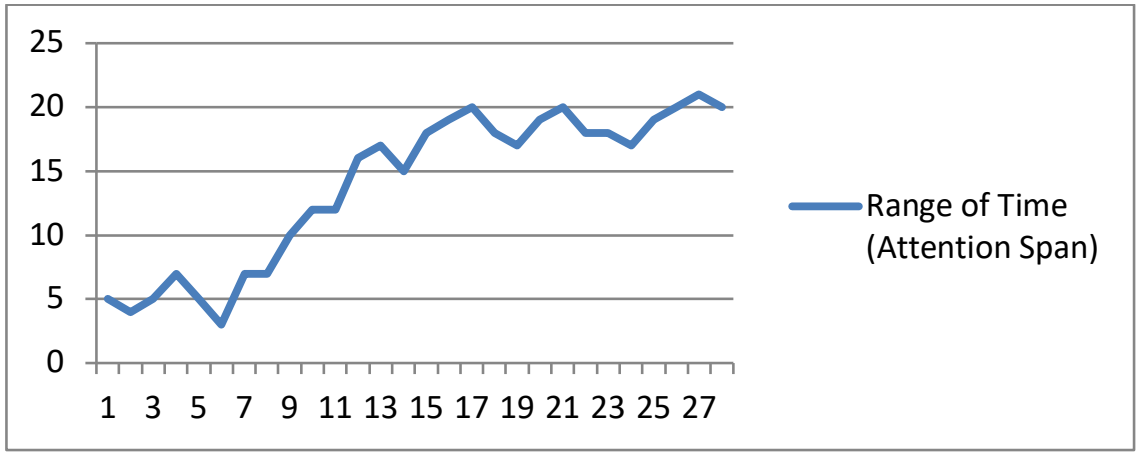

Figure 2: The increase of time range in school task completion

Note:

$\mathrm{X}$ axis: Time range of task completion (minutes)

Y axis: Day (Baseline: 1-6; Intervention: 7-21, Follow-up: 22-28)

Table 3. Statistical analysis of time range in school task completion

\begin{tabular}{llllll}
\hline Phase & $\mathrm{N}$ & Mean & Std. Deviation & Minimum & Maximum \\
\hline Baseline & 6 & 4.8333 & 1.32916 & 3.00 & 7.00 \\
\hline Intervention & 16 & 15.3125 & 4.37750 & 7.00 & 20.00 \\
\hline Follow-up & 6 & 19.1667 & 1.47196 & 17.00 & 21.00 \\
\hline
\end{tabular}

Table 4. Results of statistical analysis of the time range increase of school task completion

\begin{tabular}{llll}
\hline & $\begin{array}{l}\text { Intervention- } \\
\text { Baseline }\end{array}$ & $\begin{array}{l}\text { Follow Up- } \\
\text { Intervention }\end{array}$ & Follow Up-Baseline \\
\hline $\mathrm{Z}$ & $-2.207^{\mathrm{a}}$ & $-2.207^{\mathrm{a}}$ & $-2.226^{\mathrm{a}}$ \\
\hline $\begin{array}{l}\text { Asymp.Sig. } \\
\text { (2-tailed) }\end{array}$ & .027 & .027 & .026 \\
\hline
\end{tabular}


a. Based on positive ranks

b. Wilcoxon Signed Ranks Test

The above Statistical analysis shows that there were significant differences between the baseline phase and the intervention phase, with a value of $p=0.027(p<0.05)$, so was with the follow-up phase and the intervention phase with the value of $p=0.027(p<0.05)$, and the difference between the follow-up phase with the baseline phase indicated by the value of $\mathrm{p}=0.026(\mathrm{p}<0.05)$

\subsubsection{Time range of task completion at home}

Through the given behaviour therapy by the parents, one of the measurable implications is that the subject increased the attention span of task completion at home. He could sit quiet for much longer and his hyperactivity behaviour was reduced. Prior to the implementation of the intervention, the length time that the subject could sit quietly studying with his mother was 5-10 minutes, and after the intervention the subject could sit quietly for studying for 1520 minutes. The development recorded by the mother is presented in the following graph.

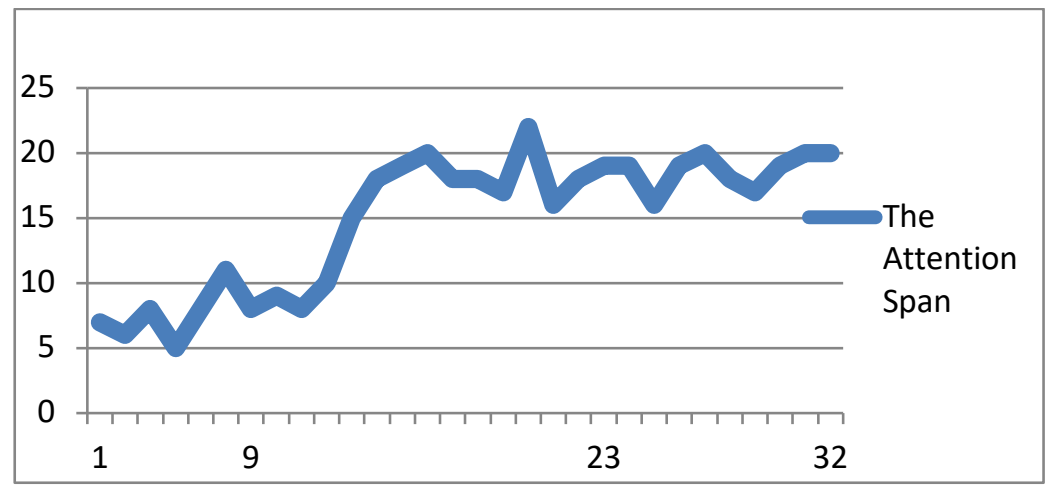

Figure 3: The increase of time range in home task completion

Note:

$\mathrm{X}$ axis : Time range of attention span (minutes)

$\mathrm{Y}$ axis : Day

Table 5. Statistical analysis of time range of home task completion

\begin{tabular}{llllll}
\hline Phase & $\mathrm{N}$ & Mean & Std. Deviation & Minimum & Maximum \\
\hline Baseline & 6 & 7.5000 & 2.07364 & 5.00 & 11.00 \\
Intervention & 14 & 15.4286 & 4.70212 & 8.00 & 22.00 \\
Follow-up & 10 & 18.7000 & 1.33749 & 16.00 & 20.00 \\
\hline
\end{tabular}

Table 6. Results of statistical analysis on the increase of time range of home task completion

\begin{tabular}{llll}
\hline & Intervention-Baseline & Follow Up-Intervention & Follow Up-Baseline \\
\hline $\mathrm{Z}$ & $-2.032^{\mathrm{a}}$ & $-2.199^{\mathrm{a}}$ & $-2.207^{\mathrm{a}}$ \\
\hline Asymp.Sig. (2-tailed) & .042 & .028 & .027 \\
\hline
\end{tabular}

a. Based on positive ranks

b. Wilcoxon Signed Ranks Test 
Statistical analysis showed that there were significant differences in the attention span of task completion at home during the baseline phase and the intervention phase indicated by the value of $p=0.042(p<0.05)$, as well as significant differences between the follow-up and baseline phases indicated by the value of $p=0.027(p<0.05)$.

\subsection{Discussion}

The essential feature of ADHD is a persistent pattern of attention and/or hyperactivity-impulsivity that interferes with functioning or development. Inattention manifest behaviorally in ADHD as wandering off task, lacking persistence, having difficulty sustaining focus, and being disorganized and is not due to defiance or lack of comprehension. Hyperactivity refers to excessive motor activity (such as a child running about) when it is not appropriate, or excessive fidgeting, tapping or talkativeness ((APA), 2013). ADHD is a chronic disease that affects the functions at school, home, and community, so it is very important to do treatments as soon as possible (Barkley, 2006).

This study determines the effectiveness of psychosocial behavioral therapy using antecedents consequences modification in lowering the hyperactivity and increases the attentiveness for children with ADHD. The present research proved that the hyperactivity decreased significantly $(\mathrm{p}=$ $0.024, p<0.05$ ), attentive behavior to sit for a long-time doing tasks in school increased significantly ( $\mathrm{p}=0.026, \mathrm{p}<0.05$ ), and attentive behavior of sitting for long time working on tasks at home also increased significantly with the value of $p=0.027(p<0.05)$.

In this study, intervention used psychosocial behavioral treatments with modifying antecedents and consequences. One of the interventions that are quite successful in lowering hyperactivity and increasing attention span of ADHD children is psychosocial behavioral interventions. Teacher and parents as significant person to conduct the behavior therapy (Linda J Pfiffner et al., 2015; Tresco, Lefler, \& Power, 2010). There is some reason why psychosocial behavioral treatment effective to treat children ADHD, first because psychosocial treatments focus on these problems rather than the core symptoms. It will help children with ADHD cope the situations in daily life. Second, the psychosocial behavioral treatments will teach parents and teachers how to overcome with the children's impairments and are useful for a child's lifetime (Center for Children and Families, 2019).

In psychosocial treatments, teacher and parents conducted the behavioral therapy (Tresco et al., 2010). The principle of the behavioral therapy is changing the antecedents and consequences. Antecedents is a term describing the environment or the events that affect the occurrence of the behavior. For example, the teacher gives orders that would probably affect the behavior of students. The environment of the classroom (e.g., structured and predictable class rules) had significant effects on students' behavior. Consequences can be described as any of the following behaviors and affecting the increase or decrease of the behavior.

In this study, modifying antecedents by the parents at homes lies on several rules by the parents. Rules will give cues to the child what behavior they should do. After the child showed expected behaviors, parents should reinforce adaptive behaviors with positive reinforcements (hug, kisses and praises). At school, teachers give him several rules as cues how he should behave. After the child showed expected behaviors, teachers gave several reinforcements, praise and stamp of train as his favorites. This strategy is aimed at increasing the frequency of appropriate and adaptive behaviors and has been demonstrated to be an effective strategy for changing behavior ( $\mathrm{Jr}$, 
Fabiano, \& Pelham, 2008). The success of this therapy was related to the support and great consistency of parents and teachers. As explained on the methods, that the parties implemented this behavior therapy are teachers and parents that were directly interacting with, providing rules for, and providing reinforcement for the subject. Factors determining the success of the therapy on ADHD children are strong commitments of parents and teachers on the plan that has been arranged and has a great willingness to really implement antecedents-consequences modifications on the children. This is because children have to look at the system of consequences in places associated with adults and happens every day (Tresco et al., 2010). In this study, teachers and parents consistently applied the regulations that had been planned and provided reinforcement on what the subject has promised. The subject learned how to behave both at home and at school. This was what made the therapy process run smoothly and showed a significant progress on the subject within 1 month.

The basic components in the modification antecedents-consequences program is abbreviated as CISS-4 (Tresco et al., 2010). The component consists of Consistency, Immediacy, Specificity, and Saliency. Consistency refers to the adherence to a specific behavior plan. In this study, parents and teachers consistently applied regulations and give consequences of what the subject had promised. Immediacy means consequences should be given to the child as soon as possible after the behavior occurs. A gap of time between behavior and consequence will result in ineffective interventions. The subject get reinforcement when he managed to run the rules given by the teacher. Specify refers to parents and teachers revealing explicitly and clearly on target interventions that will result in specific consequences. Parents and teachers provided the regulations explicitly on the subject of how he should behave. In addition, teachers and parents provided pictures of examples of good behavior mounted on the wall. This sample image can be a prompt to provoke the behavior of the subject. Saliency refers to the facts if the consequences should be meaningful, important, and attention drawing for the subject (Tresco et al., 2010). Thus, interventions on children's cases need modification of antecedent consequences that will vary slightly between one child to another. Therefore, studies on children in need are often single case study (Shriver et al., 2011). In this study, the subject likes trains and the figure of the affection of the mother, therefore the consequence given by teachers at the school when the subject managed to sit long task was the train pictorial stamp. The more perfect he did his duty, more and more of a train stamp he got. Likewise, with planning the task at home, where the subject was very close to his mother and very fond of more attention from his mother and father. Therefore, reinforcement such as hugs and kisses were very favored by the subject. By applying 4 principles in carrying out behavioral therapy based on antecedents-consequences modification, the success percentage of the intervention increased.

This result in line with previous study about effectivity of psychosocial behavioral treatments using antecedents-consequences modifications (Evans, Steven W; Owens, Julie; Bunford, 2014; Linda J. Pfiffner et al., 2014). Other behavioral therapy modification studies for ADHD as also stated that behavior intervention for students with ADHD were very effective if include antecedent-consequence-based strategies (Barkley, 2006). The rules become very important and weak responses on the environment is fundamental to the emergence of ADHD. The intervention includes behavior modification of the environment that are directly targeted on the weakness. An intervention based on antecedent has been widely used to prevent the inattention and disruptive behaviors. First of all, the teacher can put class rules on a convenient spot (DuPaul \& Weyandt, 2006). Regulation should be fewer and contain the positive behaviour (for example asking stu- 
dents what to do, not only the behaviour that should be avoided), and puts the regulation on convenient spots so that it can be viewed by all students. Furthermore, teachers should regularly praise the students who follow the rules. Children with ADHD need regulation that is more intense and must be provided with more corpulent praise when following the rule (Pfiffner, Linda J; Barkley, R; DuPaul, 2006).

The antecedent-based strategy is frequently recommended for students with ADHD to increase engagement on task completion through modifying the content or the time range (DuPaul, George; Stoner, 2003). Reducing the length of the task completion is associated with the student's attention span that might decrease off-task behaviour, and disruptive behaviour. This strategy is often paired with teachers' compliment upon the completed task. As long as students demonstrate their success in doing tasks, the time range of task completion can be increased in order to help the behaviour of doing school task and following the regulations.

\section{CONCLUSION}

This research gave evidence that psychosocial behavior therapy using antecedent-consequences modification is effective to decrease hyperactivity and improve span of attention to child with ADHD. Parents and teachers as significant person to conduct behavior therapy with modifying antecedents and consequences. Another important thing is not about the therapy itself, but also how therapy is delivered. Consistency, Immediacy, Specificity, and Saliency were needed to make the therapy succeed. Not only about that, the consequences should concern to something meaningful to the child. More meaningful consequences to the child, more behavior that are expected emerge. Further research is suggested to do follow-up after several months after the intervention (e.g six months). Follow up is needed to find out whether the parents and teacher still conduct the behavior therapy and how the impact to the child.

\section{REFERENCE}

(APA), A. A. P. (2013). Diagnostic and Manual of Mental Disorder (5th ed.). Arlington: American Psychiatric Association.

Amalia, R. (2018). Intervensi terhadap Anak Usia Dini yang Mengalami Gangguan ADHD Melalui Pendekatan Kognitif Perilaku dan Alderian Play Therapy. Jurnal Obsesi : Jurnal Pendidikan Anak Usia Dini, 2(1), 27. https://doi.org/10.31004/obsesi.v2i1.4

Anastopoulos, A.D; Farley, S. . (2003). A Cognitive Behavioural Training Program for Parents of Children with Attention-Deficit/Hyperactivity Disorder. In W. J. Kazdin, Alan E (Ed.), Evidence-based psychotherapies for children and adolescents (pp. 187-203). New York: Guildford Press.

Barkley, Russell A; DuPaul, G.L; McMurray, M. . (1990). A comprehensive evaluation of attention deficit disorder with and without hyperactivity. Journal of Consulting and Clinical Psychology, 58, 775-789.

Barkley, R. A. (2006). Attention-deficit hyperactivity disorder: A handbook for diagnosis and treatment (3rd ed.). New York City: Guildford Press.

Barlow, D.H; Hersen, M. (1984). Single case experimental design: Strategies for studying behavior change (2nd ed.). New York: Pergamon Press.

Baumeister, S., Wolf, I., Holz, N., Boecker-Schlier, R., Adamo, N., Holtmann, M., ... Brandeis, D. (2018). Neurofeedback Training Effects on Inhibitory Brain Activation in ADHD: A Matter of Learning? Neuroscience, 378, 89-99. https://doi.org/10.1016/j.neuroscience.2016.09.025

Cantwell, D. P., \& Baker, L. (1991). Association between attention deficit-hyperactivity disorder and learning disorders. Journal of Learning Disabilities, 24(2), 88-95. 
https://doi.org/10.1177/002221949102400205

Center for Children and Families. (2019). Evidence-based Psychosocial Treatment for ADHD Children and Adolescents. Retrieved from http://ccf.fiu.edu

Davidson, G. C. (2010). Abnormal Psychology. New Jersey: Wiley.

DuPaul, George; Stoner, G. (2003). ADHD in the schools. New York: Guildford Press.

DuPaul, G., \& Weyandt, L. (2006). School-based intervention for children with attention deficit hyperactivity disorder: Effects on academic, social, and behavioural functioning. International Journal of Disability, Development and Education, 53(2), 161-176. https://doi.org/10.1080/10349120600716141

Erinta, D. B. M. S. (2012). Efektivitas penerapan terapi permainan sosialisasi untuk menurunkan perilaku impulsif pada anak dengan attention deficit hyperactive disorder (ADHD). Jurnal Psikologi : Teori \& Terapan, 3(1).

Evans, Steven W; Owens, Julie; Bunford, M. N. (2014). Evidence-Based Psychosocial Treatments for Children and Adolescents with Attention-Deficit/Hyperactivity Disorder. Journal Clinical Child Adolescence Psychology, 43(4), 527-551. https://doi.org/10.1038/jid.2014.371

Fabiano, G. A., Pelham, W. E., Coles, E. K., Gnagy, E. M., Chronis-Tuscano, A., \& O'Connor, B. C. (2009). A meta-analysis of behavioral treatments for attention-deficit/hyperactivity disorder. Clinical Psychology Review, 29(2), 129-140. https://doi.org/10.1016/j.cpr.2008.11.001

Gerdes, A. C., Hoza, B., \& Pelham, W. E. (2003). Attention-deficit/hyperactivity disordered boys' relationships with their mothers and fathers: Child, mother, and father perceptions. Development and Psychopathology, 15(2), 363-382. https://doi.org/10.1017/S0954579403000208

Haas, S. M., Waschbusch, D. A., Pelham, W. E., King, S., Andrade, B. F., \& Carrey, N. J. (2011). Treatment response in CP/ADHD children with callous/unemotional traits. Journal of Abnormal Child Psychology, 39(4), 541-552. https://doi.org/10.1007/s10802-010-9480-4

Helseth, S. A., Waschbusch, D. A., Gnagy, E. M., Onyango, A. N., Burrows-MacLean, L., Fabiano, G. A., ... Pelham, W. E. (2015). Effects of behavioral and pharmacological therapies on peer reinforcement of deviancy in children with ADHD-Only, ADHD and conduct problems, and controls. Journal of Consulting and Clinical Psychology, 83(2), 280292. https://doi.org/10.1037/a0038505

Hidayati, DM Ria; Purwandari, E. (2010). Time Out: Alternatif Modifikasi Perilaku Anak ADHD (Attention Deficit/ Hyperacitivity Disorder). Indigenous, Jurnal Ilmiah Berkala Psikologi, 12(2), 101-114.

Hinshaw, S. P., Owens, E. B., Wells, K. C., Kraemer, H. C., Abikoff, H. B., Arnold, L. E., ... Wigal, T. (2000). Family processes and treatment outcome in the MTA: Negative/ineffective parenting practices in relation to multimodal treatment. Journal of Abnormal Child Psychology, 28(6), 555-568. https://doi.org/10.1023/A:1005183115230

Hinshaw, Stephen P., Owens, E. B., Zalecki, C., Huggins, S. P., Montenegro-Nevado, A. J., Schrodek, E., \& Swanson, E. N. (2012). Prospective follow-up of girls with attentiondeficit/hyperactivity disorder into early adulthood: Continuing impairment includes elevated risk for suicide attempts and self-injury. Journal of Consulting and Clinical Psychology, 80(6), 1041-1051. https://doi.org/10.1037/a0029451

Jackson, N. A. (2003). A Survey of Music Therapy Methods and Their Role in the Treatment of Early Elementary School Children with ADHD. Journal of Music Therapy, 40(4), 302-323. https://doi.org/10.1093/jmt/40.4.302

Johnston, Charlotte; Mash, E. J. (2001). Families of Children With AttentionDeficit/Hyperactivity Disorder: Review and Recommendations for Future Research. Clinical Child and Family Psychology Review, 4(3), 183-207.

Jr, W. E. P., Fabiano, G. A., \& Pelham, W. E. (2008). Evidence-Based Psychosocial Treatments for Attention- Deficit / Hyperactivity Disorder (Vol. 4416). https://doi.org/10.1080/15374410701818681

Kaiser, N. M., McBurnett, K., \& Pfiffner, L. J. (2011). Child ADHD severity and positive and 
negative parenting as predictors of child social functioning: Evaluation of three theoretical models. Journal of Attention Disorders, 15(3), 193-203. https://doi.org/10.1177/1087054709356171

Kazdin, A. E. (1984). Behavior Modification in Applied Settings. New York: Dorsey Press.

Krasny-Pacini, A., \& Evans, J. (2018). Single-case experimental designs to assess intervention effectiveness in rehabilitation: A practical guide. Annals of Physical and Rehabilitation Medicine, 61(3), 164-179. https://doi.org/10.1016/j.rehab.2017.12.002

Langberg, J. M., Molina, B. S. G., Arnold, L. E., Epstein, J. N., Altaye, M., Hinshaw, S. P., ... Hechtman, L. (2011). Patterns and predictors of adolescent academic achievement and performance in a sample of children with attention-deficit/hyperactivity disorder. Journal of Clinical Child and Adolescent Psychology, 40(4), 519-531. https://doi.org/10.1080/15374416.2011.581620

Nigg, J.T ; Barkley, R. . (2014). (Attention-deficit Hyperactivity Disorder). In R. A. Barkley (Ed.), E-book Pediatric เรื่อง Psychiatry (Third Edit, Vol. 54, pp. 1-17). Retrieved from http://www.thaipediatrics.org/pages/Doctor/Download/48aedb8880cab8c45637abc7493ec ddd:e0a186938dc3b74657fd46d32fac5fe6

Pastor, P., Reuben, C., Duran, C., \& Hawkins, L. J. (2015). Association between diagnosed ADHD and selected characteristics among children aged 4-17 years: United States, 20112013. NCHS Data Brief, (201), 201.

Patterson, G. . (1982). Coercive Family Process. Eugene: Castalia.

Pfiffner, L. J ; Barkley, R. . (1990). Educational Placement and Classroom Management. In R. A. Barkley (Ed.), Attention Deficit Hyperactivity Disorder: A Handbook for Diagnosis and Treatment. New York: Guildford Press.

Pfiffner, Linda J; Barkley, R; DuPaul, G. (2006). Treatment of ADHD in school settings. In R. A. Barkley (Ed.), Attention-deficit hyperactivity disorder: A handbook for diagnosis and treatment (3th ed., pp. 547-589). New York: Guildford Press.

Pfiffner, L. J., Calzada, E., \& McBurnett, K. (2000). Interventions to enhance social competence. Child and Adolescent Psychiatric Clinics of North America, 9(3), 689-709. https://doi.org/10.1016/s1056-4993(18)30113-5

Pfiffner, Linda J., Hinshaw, S. P., Owens, E., Zalecki, C., Kaiser, N. M., Villodas, M., \& McBurnett, K. (2014). A two-site randomized clinical trial of integrated psychosocial treatment for ADHD-inattentive type. Journal of Consulting and Clinical Psychology, 82(6), 1115-1127. https://doi.org/10.1037/a0036887

Pfiffner, Linda J, \& Haack, L. M. (2014). Behavior Management for School-Aged Children with ADHD. 23, 731-746.

Pfiffner, Linda J, Hinshaw, S. P., Owens, E., Zalecki, C., Kaiser, N. M., Villodas, M., \& Mcburnett, K. (2015). A two-site randomized clinical trial of Integrated Psychosocial Treatment for ADHD-Inattentive Type. Journal of Consulting and Clinical Psychology, 82(6), 1115-1127. https://doi.org/10.1037/a0036887.A

Riddle, M. A., Yershova, K., Lazzaretto, D., Paykina, N., Yenokyan, G., Greenhill, L., ... Posner, K. (2013). The preschool attention-deficit/hyperactivity disorder treatment study (PATS) 6year follow-up. Journal of the American Academy of Child and Adolescent Psychiatry, 52(3). https://doi.org/10.1016/j.jaac.2012.12.007

Saputro, D. (2009). ADHD (Attention Deficit/ Hyperactivity Disorder). Jakarta: Sagung Seto.

Schunk, D. H. (2012). Learning Theories: An Educational Perspective (6th ed.; Pearson Education, Ed.). Boston.

Shriver, M. D., Segool, N., \& Gortmaker, V. (2011). Behavior observations for linking assessment to treatment for selective mutism. Education and Treatment of Children, 34(3), 389-411. https://doi.org/10.1353/etc.2011.0023

Suyanto, B. N., \& Wimbarti, S. (2019). Program Intervensi Musik terhadap Hiperaktivitas Anak Attention Deficit Hyperactivity Disorder (ADHD). Gadjah Mada Journal of Professional Psychology (GamaJPP), 5(1), 15. https://doi.org/10.22146/gamajpp.48584

Taylor, E. (2009). Developing ADHD. Journal of Child Psychology and Psychiatry, 50, 126132. 
Thomas, R., Sanders, S., Doust, J., Beller, E., \& Glasziou, P. (2015). Prevalence of attentiondeficit/hyperactivity disorder: A systematic review and meta-analysis. Pediatrics, 135(4), e994-e1001. https://doi.org/10.1542/peds.2014-3482

Tran, J. L. A., Sheng, R., Beaulieu, A., Villodas, M., McBurnett, K., Pfiffner, L. J., \& Wilson, L. (2018). Cost-Effectiveness of a Behavioral Psychosocial Treatment Integrated Across Home and School for Pediatric ADHD-Inattentive Type. Administration and Policy in Mental Health and Mental Health Services Research, 45(5), 741-750. https://doi.org/10.1007/s10488-018-0857-y

Tresco, K. E., Lefler, E. K., \& Power, T. J. (2010). Psychosocial Interventions to Improve the School Performance of Students with Attention-Deficit/Hyperactivity Disorder. Mind \& Brain: The Journal of Psychiatry, 1(2), 69-74. Retrieved from http://www.ncbi.nlm.nih.gov/pubmed/21152355\%0Ahttp://www.pubmedcentral.nih.gov/a rticlerender.fcgi?artid=PMC2998237

U.S. Department of Health and Human Services. (2014). US Department of Health and Human Services. The Health and Well-Being of Children: A Portrait of States and the Nation, 20112012. (June), 1-109.

Weiss, Gabrielle; Hechtman, L. T. (1993). Hyperactive Children Grown Up. New York: Guildford Press. 